\title{
Emerging of cysticercosis in Europe: a concern
}

\author{
Beuy Joob · Viroj Wiwanitkit
}

Received: 13 May 2012/Accepted: 21 May 2012/Published online: 6 June 2012

(C) Belgian Neurological Society 2012

Sir, we read the recent publication on neurocysticercosis with a great interest [1]. There are several points that should be discussed. Del Brutto et al. [1] concluded that "The prevalence of neurocysticercosis in Western Europe may be on the rise." To support this conclusion, there should be a comparative data to confirm the increasing trend of cysticercosis. Also, Del Brutto et al. [1] mentioned that "It is possible that some patients had acquired the disease as the result of contact with Taenia solium carriers coming from endemic countries." This has to be carefully considered. Cysticercosis is classified as a food-borne disease [2], not a disease that can be person to person transmitted. Cysticercosis is not taeniasis, hence, contact with carriers should not lead to cysticercosis.

Conflict of interest None.

\section{References}

1. Del Brutto OH (2012) Neurocysticercosis in Western Europe: a re-emerging disease? Acta Neurol Belg. doi:10.1007/s13760012-0068-3

2. Waikagul J, Dekumyoy P, Anantaphruti MT (2006) Taeniasis, cysticercosis and echinococcosis in Thailand. Parasitol Int 55(Suppl):S175-S178

B. Joob $(\bowtie)$

Sanitation 1 Medical Academic Center, Bangkok, Thailand

e-mail: beuyjoob@hotmail.com

V. Wiwanitkit

Wiwanitkit House, Bangkhae, Bangkok, Thailand 